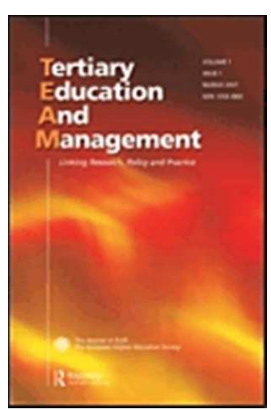

The performance evaluation of corporate universities

\begin{tabular}{|r|l|}
\hline Journal: & Tertiary Education and Management \\
\hline Manuscript ID & RTEM-2016-0064.R1 \\
\hline Manuscript Type: & Original article \\
\hline Keywords: & $\begin{array}{l}\text { higher education, corporate universities, knowledge management, } \\
\text { performance evaluation }\end{array}$ \\
\hline \multicolumn{2}{|l}{} \\
\hline
\end{tabular}

SCHOLARONE $^{\text {m }}$

Manuscripts 


\section{The performance evaluation of corporate universities}

\section{Introduction}

Corporate universities (COU) are an emerging phenomenon in higher education.They are a peculiar arrangement for integrating ${ }^{1}$ and exchanging knowledge within firms between firms and external environment in presence of incessant structural changes (technological, organizational and institutional). The COUs are aimed at connecting learning processes with strategic objectives by allowing firms to promote full codified knowledge and general education, while, at the same time, to embody training contents in the organizational context. Historically, the COUs born in the United States where the phenomenon has been experiencing a systematic development to reach the current diffusion, approximately quantified in 4000 units (McAteer \& Pino, 2011). In parallel, a worldwide spread of COUs occurred, in particular in Western Europe, where active COUs are estimated to exceed 200 almost doubling in the last decade if compared with the number reported in the early 2000s at least 30 of which are established in Italy (Cappiello and Pedrini, 2013).

The COU label is currently attached to a broad range of entities, ranging from renamed training departments to institutionalized carriers of strategic knowledge within and between the | organizations. Actually, the COUs, can be placed on a path of evolutionary growth represented by an ideal stair starting from the training department and ending up with an autonomous organization competing with traditional universities_(Allen, 2002). As such, although COUs and traditional universities have different aims, scopes and values, the COU can be considered as part of a broadly defined HE sector. Indeed, the COU substantially differs from the traditional "training and development" departments because they go beyond the provision of technical idiosyncratic skills and organizational culture by providing courses that are typical of post-school education (El-Tannir, 2002). In particular, the COU is a mean for acknowledging the central role of certain competences in sustaining the long-term growth of the firm and can be seen as a potential catalyst of knowledge able to pursuit a sustainable competitive advantage through its two cornerstone: the strategic role and the capability to integrate knowledge in order to address innovation and change (Rheaume and Gardoni, 2015).

COUs, like other institutions, have a strong need of conducting appropriate evaluation in order to improve their efficiency and effectiveness in pursuing and reaching their objectives, which,

| ${ }_{-}^{1}$ We refer to the broad definition of knowledge integration proposed by Grant (1996) 
however, are different than those of traditional universities, on the one hand, and of standard training departments, on the other hand. Not surprisingly, despite the relevance of performance evaluation for the COU and the call for a balanced approach "mixing both quantitative and qualitative criteria" (Morin and Renaud, 2004, p. 305) the measurement of the overall effect of $\underline{\text { COU activities has been proven to be a difficult task (Bober and Barlett, 2004). Once acknowledged }}$ the heterogeneity of the COU formats both in theory and practice, the issue to be addressed is what kind of performance evaluation system is more able to improve COUs' efficiency and effectiveness with respect to the institutional objectives underlying each variety of COU. In order to address this research question, we use data of a survey on Italian COUs by looking at the organizational members that evaluates the COU, the external stakeholders involved in COUs' activities, and the criteria used for the evaluation assessment. This paper thus contributes to the existing literature by establishing a relationship between COU evaluation systems and the different categories of COUs. More than one theory could provide a suitable framework for analysing the evaluation of COU's activities. Although the stakeholder-based approach is the one that potentially enables all the multiple categories of actors that are interested in the COU's performance to be involved in the evaluation process when the COU actively exchange knowledge with the external environment, notably by partnering with traditional universities, the reality of $\mathrm{COU}$ is too complex to stick to a one size fits all solution.

The paper is structured as follows. Section 2 reviews the literature on the COUs and highlight those specific aspects that should be taken into account in designing evaluation systems and the purposes underlying the use of the results by the management of the parent company. Section 3 propose an ad-hoc taxonomy that can provide a rational for the different evaluation system actually used by the COUs. Section 4 describes the survey we delivered to Italian COUs. Section 5 discusses the results. Section 6 concludes.

\section{The COU as both an organizational unit and a higher education institution}

In the literature, a widely accepted definition of COU is still missing and even the same term "corporate university" is in some way problematic. The main difficulty with accurately defining it rests on the diverse range of projects entity that are labelled with this term and on the tension relationship between COUs and traditional universities-is also different. In most of the cases the term "university" is used more "as a metaphor for outlining the importance of its learning initiatives and for branding the organizations' educational programs" (Maglione and Passiante, 2009, 104) 
than for an actual attempt to transplant the model of a traditional university into a company. Walton $(2005$, p. 8) even argues that "virtually no COU would meet the requirements set out in dictionary definitions of the word "university", nor would they wish to". Still now, despite the further and diffusion and development of the phenomenon, there is little evidence of convergence between entities coming from different roots and traditions. Nor the COUs do have a formal legal status or a common worldwide standard if analysed as a standalone model. We find both higher education institutions founded by corporations that offer academic courses or credit, mainly in the US, and inhouse training centres that offer programs for their parent company's employees, which is the most common outcome in Europe.

When looking at specific definitions, one can divide them in two broad categories. The first one looks at the COU as a peculiar educational institution. The oldest definition of $\mathrm{COU}$ defines it as an "educational institution providing training courses on behalf of an organization whose mission has nothing to do with education" (Eurich, 1985 p. 23). The COU is placed within a broadly defined higher education system as an entity that mainly provides a teaching function through programs focused on the provision of technical and/or soft competences to parent company's staff and the employees of their partners (Jarvis, 2001) and defined an "educational entity designed to assist its parent organization in achieving its mission by conducting activities designed to cultivate individual and organizational learning, knowledge, and wisdom" (Allen, 2002, p. 14) which is "the natural alternative to employee education at work and after college" (El-Tannir, 2002, p. 77) by "promoting the development of the individuals in a bid to improve teamwork business skills, leadership and relationship with suppliers, furthermore it can constitute a pathway for research" (Rheaume and Gardoni, 2015). It can thus exceed corporate boundaries to provide educational services, receive external accreditation, and eventually act as a proper university issuing legally recognized diplomas. In this respect they are viewed as either potential rivals of colleges and tertiary education institutions to the extent that their programs overlap and duplicate each other or an answer to the companies' concerns about the capabilities of traditional university to provide new employees with the skills they need to proper accomplish their job tasks given that the incessant change that eharacterizes the competitive environment in which organisations operate (Rowley et al., 1998). Still, its rationale and underlying philosophy rests far from the one of traditional universities (Walton, 2005) compared to which they serve different purposes and take different forms, while actually working more often in partnership rather than in competition with public universities (Blass, 2001). Differently from training centres, they go beyond the provision of technical 
idiosyncratic skills and organizational culture, but they also intervene on general contents by providing courses focused on the development of managerial and communication skills as well as of ether contents that are typical of post-school education. On the other hand, the second group of definitions focuses on the relationship with business strategies: the COU "grows when a company tries to relate their strategies for training and human resource development with the overall business strategy, through the coordination, integration and development of human capital within organization" (Henley Management College, 2005, p. 8), and is configured as a "strategically useful tool to ensure that an organization achieves its mission" (Moore, 2002, p. 32) and "strategic umbrella of business for educating not only employees, but also secondary customers and suppliers" | (Meister, 1998, p. 29).

In any case the COU does not exist as stand-alone entity at least at its foundation. The COU comes into being as a part of (and provide service to) a parent organization, whose strategy inspires its mission. Outside of this core elements, the variety of definitions reflects the heterogeneity of the | phenomenon in terms of scope, activities and recipients. Indeed, the potential scope of a CU is very broad and concern "all activities that cultivate learning, knowledge and communication of those who, whether or not inside the company, can contribute directly to business success" (Moore 2002). In particular, beside the provision of training programs for parent company's, the COU can be involved, in whole or in part, in talent recruitment, change management, career paths, geographical mobility, job rotation, on-the-job training (such as mentoring and coaching), relationships with traditional universities and other educational agencies. Other possible activities are represented by, research and development (R\&D), vendor's selection process, knowledge diffusion outside the corporate (library, working papers, etc.). No COU however is involved in all these possible functions at the same time (Allen 2010). Moreover, the COU is almest unanimously conceived as an answer to organizational changes, considering that such changes have become increasingly frequent and are now able to determine a continuous mismatch between company learning ability and its pursuit of business goals. In such a conceptual framework the $C U$ is a means for acknowledging the central role of certain competences in sustaining the long term growth of the firm. This is particularly true with reference to the development of relational competences and corporate culture (Blass 2005) while it is partially applicable to managerial and idiosyneratic technical skills. Aceordingly, the COU can thus be seen as a potential catalyst of knowledge able support the parent company to pursuit a sustainable competitive advantage -through its 
cornerstone: the strategic role and the capability to integrate knowledge in order to address innovation and change (Blass 2005).

In line with these features, the most typical recipients of COUs' activities are newly hired young workers and managers. Looking at the formers the $\mathrm{COU}$ can be compared to a higher education institution that looks at the organization of courses for young graduates and undergraduates as their | core business. When focusing on the latters, the COU rather acts as a Business School with the provision of initiatives dedicated to their current and future managers or to managers of firms with which the parent company cooperates such as foreign subsidiaries, suppliers, and customers. | However, the relationship with traditional universities primarily acts in terms of complementarity, with the $\mathrm{COU}$ viewed as a connecting entity between tertiary education curricula and the business domain (Wang et al., 2010) devoted to bridge the cognitive gap between the firm and the external environment, while getting value from the interaction with educational agencies and business schools. On the other hand, traditional universities could be supported by the COU in transferring research outcomes to the firms and providing tailored programs for the parent company and its network. Such complementarity is consistent with a "knowledge based" firm aiming at expanding its internal learning towards different activities and different types of human capital, awarding a strategic role to education through a greater coordination among contents, investments and performance (Ryan, 2009).

This conceptual framework, made even more complex by the wide spectrum of organizations that have created their own COU (multinationals, medium firms, non-profit organizations, state-owned agencies), has led to an increasing heterogeneity of the phenomenon. The literature has addressed this complexity in practiceby developing different taxonomies focusing on specific aspects of these entities. The most popular one has been proposed by Allen (2002), who identifies four levels of COUs placed on a path of growth (the so-called "Allen ladder") that grounds on the set of activities attributed to the COU and on COU external recognition. Other taxonomies divide the COUs according to their training subjects (Antonelli et al., 2013), their objectives and activities (Rademakers, 2005), and their approach to innovation (Rheaume and Gardoni, 2015). which has been exacerbated by the wide spectrum of organizations that have created their own COU: multinationals, medium firms, non-profit organizations, state-owned agencies. This complexity has led to the development of different taxonomies focusing on specific aspects of these entities. The most popular one has been proposed by Allen (2002), who identifies four levels of COUs placed on 
a path of growth (the so-called "Allen ladder") that grounds on the set of activities attributed to the COU and on COU external recognition:

1. Level 1: the $\mathrm{COU}$ is comparable to a stand-alone training centre that provides training on specific skills attached to job tasks;

2. Level 2: the COU extends itshis intervention to management/executive development and to strategic needs of the parent organization;

3. Level 3: the COU provides courses that allow students to get academic credits. Credits are usually recognized in a degree or a master course offered by a traditional university;

4. Level 4: the COU provides training packages that allow students to get an academic degree. This taxonomy, however, partly disregards the issue of training contents, without distinguishing among different categories of skills (Wang et al., 2010). Indeed, if we look at programs, we can identify three different types of COU:

1. "generalist". The COU is entitled to deliver all training contents, including general skills and corporate culture. Such a $\mathrm{COU}$ is primarily designed to provide post tertiary education to young graduates, and to retain employees.

2. "managerial". The COU develops both managerial and behavioural skills in order to create long lasting managers, endowed with advanced leadership skills in line with corporate strategy.

"technical". The COU focuses on creation, diffusion and maintenance of specific technical skills. The boundaries among these categories are, however, fuzzy because a large proportion of a firm's strategic expertise is related to different types of knowledge, disseminated throughout the organization through non-formal channels. Finally, a third taxonomy focuses on COU's objectives and activities, identifying three possible "labels" (Rademakers, 2005):

1. "School": the $\mathrm{COU}$ is devoted to individuals, whose skills are upgraded in response to the company's strategy. Only training activities are attributed to the $\mathrm{COU}$;

Z. "College": the COU redistributes knowledge throughout the organization by aligning individual knowledge to organization's goals, even developing their mutual interaction (for instance via corporate culture);

3. "Academy": the COU creates new knowledge for both individuals and the organization and reports directly to the top management. The COU supports the parent company in promoting innovation. 
This scheme also envisages an ideal development path of the COU, whose ideal point of arrival is the "Academy". Only this category, in fact, is able to trigger all those processes of creation, transformation and exchange of knowledge that may support business strategy.

Regardless of the category, the expanded scope and long-term strategic orientation of the COUs entails four main strengths compared to traditional training departments:

a) it supports organizational change and expansion into new markets;

b) it connects learning initiatives to long-term organizational objectives;

e) it devotes specific attention to organizational culture in order to disseminate it throughout the sponsoring firm and integrate the employees in the parent company;

d) there is a systematic interaction with traditional universities and other educational and training agencies.

Moreover, the literature has elaborated the models of "network COU" (Allen, 2007) and "stakeholder COU" (Allen, 2009; Margherita and Secundo, 2009). -In particular, the "stakeholder"

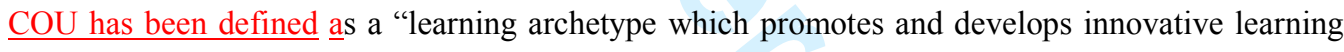
and capability-building processes among globally distributed and integrated networks of employees, customers, suppliers, partners, as well as of academics, professionals, independent learners, and other institutions" (Margherita and Secundo, 2009, p. 199), which can also play an active role in the fulfilment of fiduciary duties imposed by CSR, eventually supporting the enforcement of this selfregulatory tool (Renaud-Coulon, 2008).

Overall, the distinctive traits of the COU, which make it more complex than a traditional training department, and the variety of the COU formats that can be actually implemented, are the distinguishing factors that help us to focus our research question. On the one hand, they emphasize the importance of the evaluation system for these entities in order to objectively demonstrate the achieved results. On the other hand, they raise the need to apply different models according to their specific scope and objectives.

\section{The evaluation of COU's efficiency and performance}

The issue of measuring COU's performances and link them to the management evaluation is strategic. The financial and organizational commitment of the sponsoring firm implies that the COU must provide evidence of the results achieved in comparison with the objectives and the mission set up by the top management of the parent company itself who have a strong interest in understanding how the COU is contributing to organizational performances. Accordingly, "a reliable and solid 
evaluation system can make a difference to the perception of a COU's value and credibility by showing that it contributes to results" (Guerci et al., p. 292).

At a first glance the topic can be traced back to the literature on training evaluation systems among which the most popular one stems from the hierarchical approach proposed by Kirkpatrick (1994) which is based on four ordered levels: 1) reactions of the participants, 2) their learning, 3) the degree of transfer on actual work performance, 4) contribution to organizational performance. This model has been then extended by including a fifth level that can include either more refined financial measures of the effects on organizational performance (Philips, 1995) such as the rate of return of the investment (ROI) in training, or measures that take into account the effects of training programs on the value creation for a larger audience, that can include other competitive forces, such as customers, or even the whole society.

The use of the hierarchical model in evaluating a COU is, however, insufficient. First, the COU evaluation system should also take into account the higher complexity of the learning systems, the focus more on organizational goals, and the larger number of stakeholder that are involved in the COU activities (Kiely, 2002; Bober and Bartlett, 2004; Guerci, 2011). Indeed, in the COU one can find a larger number of "groups and constituencies that have an interest and stake in the evaluation findings and their use" (Patton, 1997, p. 354): the management of the parent company, that can be different from the one of the $\mathrm{COU}$, the partner's institutions, such as educational agencies and business schools, external vendors, and local governments. Accordingly, the involvement of a wider variety of stakeholders compared to the case of an internal training office require the construction of a targeted evaluation system that address the need of taking into account the distinct concerns, perspectives, and professional languages of the categories that participate to COUs' activities and programs (Paton, 2005). Second, the hierarchical model cannot embrace all the relevant aspects of the COU performance that need to be evaluated by the managers of the parent company. Notably strategic orientation and innovation and professional development are critical elements for determining the performance of the $\mathrm{COU}$ and its managers, but cannot be attached with one or more levels of the hierarchical model (Guerci et al., 2011). Finally, the variety of purposes underlying the use of evaluation results of COU's activities is quite broad (Bober and Bartlett, 2004) including the objective of making the COU's managers accountable to the sponsoring firm.

In parallel to the mainstream model, this literature has thus identified the stakeholder-based evaluation model as a suitable alternative to encompass the need to widen the factors that are relevant for decision-makers that are called to use the results (i.e. the top management of the parent 
company). In line with these insights it has been found that the evaluation systems in the COUs tend to follow the stakeholder-based approach (Bober and Bartlett, 2004; Guerci et al., 2011). The COUs produce designed evaluation reports for each stakeholder in order to ensure that all relevant users are able to understand and utilize the assessment information by applying the appropriate method in a timely manner. In this way the evaluation of the COU grounds on its capability to satisfy the needs of all its stakeholders. On the other hand, this type of assessment is only the first step to address the possible trade-off between conflicting objectives that are typical of different categories of stakeholders.

Given the heterogeneity of the phenomenon, as proven by the different taxonomies proposed by the literature, it is not possible, however, to identify a one-fits-all evaluation system. Our view is that an appropriate set of indicators for evaluating the performance of the COU should be identified further to an assessment of the corporate universities is that of the of the treatment of knowledge. As mentioned previously COUs are specific erganizations-units aimed at integrating knowledge within the parent company that gave and between this company and the external environment. In this sense, the COU can be evaluated on the ability to produce new knowledge, as an alternative to the acquisition from the outside and from the opening / closing against other knowledge external agencies. Figure-Table 1 shows the classification that emerges by using these two criteria. There are erganizations-COUs that acquire predominantly outside knowledge to spread among employees (Follower), organizations instead have their own production of new knowledge and also spread it outside (Innovation leader); we define these empanies-units as leaders because they operate with social responsibility and contribute to the development of the territory. Intermediate forms are represented by those companies that carry out research but tend to be closed to the external | environment (R\&D Engine) or alter companies that, for some motive fail to generate new knowledge but taking rapport with other external stakeholder act as "Gatekeepers" of knowledge.

$<$ Table 1 $>$

According to this taxonomy one can view the stakeholder-based evaluation as the ground for an appropriate evaluation system of those COUs that acts as "gatekeepers", while hierarchical model | can be the basis for evaluating the "followers", once integrated with indicators that take into account the strategic orientation that characterize these entities, to the extent to which they are closer to training department and thus characterized by a passive interaction with the external 
environment. On the other hand, the "leaders" would need a more complex system that stems from the stakeholder-based model, but it needs to be integrated it with further elements that measure the extent to which the COU encourages innovation and change in the sponsoring firm as well as in the external stakeholders. In parallel, for the "R\&D engine" type a suitable evaluation system could add innovation- based indicators to a hierarchical model in order to measure the impact of the COU on the innovative performance of the parent company.

In such a scheme educational agencies, such as "traditional" -universities, would be supported by "innovation leaders" in transferring research outcomes from university to the firms while "gatekeepers" could activate spatially idiosyncratic development processes based on tacit knowledge and proximity. In both perspectives, the COU is an autonomous unit oriented to get value from the interactions with external agencies, and from the diffusion of knowledge outside the parent company. In both cases the potential added value of the COU needs appropriate measures that go beyond the traditional indicators while traditional universities, as key-external stakeholders, can be entitled to exert a quality control on the COUs with which they cooperate.

\section{The survey}

In order to empirically investigate these issues we use data coming on a survey delivered to 31 COUs formally operating in Italy $^{2}$. Given the absence of a shared definition of COU, we included in the population all the entities labeled as COU and having a parent company. Although there are fewer than in France and Germany, due to the higher share of small and medium-sized enterprises and to the limited presence of branches of foreign multinationals Italy is an interesting country due to the growing number of recently established COUs. The prevailing industries in the population are banking and insurance sectors. Three COUs belong to utilities industry (gas, electric and water), which is also characterized by high propensity to train. Other sectors represented by more than one $\underline{\mathrm{COU}}$ are telecommunications, mechanics, food and clothing. This is not surprising given the position of leadership that Italian firms operating in these sectors achieved at European and global level. Finally, two COUs belong to the pharmaceutical sector, typically characterized by intensive research and innovation activity.

${ }^{2}$ The response rate was 20 out of 31 . 
The questionnaire is divided in five parts, each of them can be referred to different aspects, following 10 out of the 13 dimensions proposed by Abel and Li (2012) in their empirical analysis of COUs in North America: Establishment (Strategy and Mission), Organization (Governance and Leadership, Structure, Financial Sources), Activities (Curriculum Offerings, Learner Population, Stage of Development), Effectiveness (Evaluation and Measurement), Partnership (Partnership with Academia, Partnership with Vendors/Outsourcing).

Questions concern both quantitative and qualitative information, with a dominance of the latter. The quantitative items are proxies of COU size, training output, and training investment respectively. | The other features are qualitative but mainly expressed in categorical items. They concerns the motivations underlying the establishment of the $\mathrm{COU}$, the decision-making process, the training contents, the recipients of COU activity, the evaluation of the COU impact, the relationships with external stakeholders. Some question is in ordered scale, while the residual questions are in nominal scale, often allowing multiple answers. Accordingly, in most of the answers the same COU is computed more than once in the aggregation of the results.

\section{Results}

\subsection{Organization and scope}

Concerning the organization of the COUs, the most common solution is the attribution of responsibility to Human Resource Department (HRD). Only 4 COUs directly depend from the top management, while no $\mathrm{COU}$ is hierarchically subordinate to R\&D function. Consistently, the decision-making process in the COU does not follow a single rule; consistent with the dominant decision to adopt a "light" structure the majority of the COUs participate only in the decisionmaking stage while delegating the implementation phase to internal departments. They The COUs act as agents only in $25 \%$ of the cases. In the most common process, the COU makes the proposals, ustually because of the expertise of their workers, to be approved by while at the top management is given the power to approve the proposals coming from the COU $(80 \%)$. This process is accompanied in $80 \%$ of the cases by a typical top-down process. Finally, about one-fifth of the sample relies on the bottom up approach for carrying out part of the tasks assigned to the COU. The funding (Table 2) is connected to the governance system, but these two issues do not overlap. Although HRD is the responsible entity for $80 \%$ of the COUs, only in $60 \%$ of cases the COU is financed via HRD budget. The same proportion of COUs draws on public funds to finance a part of 
its activities while a slightly lower percentage (55\%) enjoy ad-hoc funds allocated by the top management. Finally, a minority share of COUs finances part of their costs with contributions coming from trained students.

$<$ Table 2>

Consistently with theoretical models and European evidence, neither all Italian COUs provide the full range of educational contents, nor their students necessarily overlap with the entire workforce. Although $70 \%$ of the COUs provides activities for all levels of employees, some COU concentrates their efforts on certain recipients, and activities. Table 3 shows that managers are the main recipients, especially the middle management. Some COU even defines itself as the "Business School" of the parent company. The active participation of the managers to COU activity is usually promoted through apposite incentive schemes in order to favour their learning outcome. Less frequent, but significant, is the participation of external stakeholders. Certain COUs are concerned with customers $(30 \%)$, other ones with agents and consultants $(30 \%)$. Their expected outcome mainly deals with marketing skills and loyalty to the parent company. Other COUs look at young graduates and students (25\%), thus by undertaking talents selection-recruitment and high potentials transition towards appropriate career paths.

$<$ Table 3>

In terms of training subjects (Table 4) our results show that Italian COUs cover all the main areas. Except for information systems, half of the sample provides all types of contents. The most frequent courses deal with managerial skills, notably leadership and communication $(90 \%)$, corporate culture and mission (85\%), the latter serving in particular the goals of employees' integration and corporate identity formation. Other typical contents deal with relational skills, notably team building (75\%).

$<$ Table 4>

\subsection{Performance evaluation}

$\underline{\text { Results on performance evaluation (Table 5) confirm the issues raised by the literature showing the }}$ persistence of an indicator of learning as the main criterion for evaluating the activities carried out 
by the $\mathrm{COU}(75 \%)$, mainly measured through questionnaires delivered at the end of the courses (95\%). In $65 \%$ of the sample, this indicator is combined with recipient's satisfaction and/or with internal climate surveys. The satisfaction of the internal customer, i.e., the managers of the trainees, is assessed in $35 \%$ of the COUs. In $25 \%$ of the cases, the evaluation relies on individual or group performance. Another $15 \%$ of the COUs also perform ex-post evaluation of the skills actually acquired by trained employees. This is primarily achieved through the involvement of line managers. Finally, only one COU carries out an analysis of employees' career paths to evaluate the results of its activities.

$<$ Table 5>.

These results show that the performance measure used for the evaluation of the managers of the COUs can be partially referred to a hierarchical-based model, which, despite its limitations, is still recognized as one of the reference schemes in the discussion about the type of evaluation method that fits with a COU. In particular, we find that most of the evaluation practices focuses on Levels 1 and 2 of the hierarchical model, while a limited fraction of them appraise the impact of training | activities on individual performance (Level 3). However, Level 4, as-proxied by a qualitative assessment of the impact on the parent company, is achieved by a higher share of COUs than Level 3. Thus the judgement of the external managers exceeds the appraisal of individual performance in terms of its diffusion.

This is at odds with the assumptions of causality and increasing importance that underlies the hierarchical model (Bates, 2004), and confirms its limitations when dealing with a larger audience of users and stakeholders, and incompleteness in presence of aspects of performance that goes beyond the immediate impact on organizational and individual outcome, that is actually the case of the COU. This insight is partially supported by unstructured answers that exemplify the need to take into account the broader scope of the COU compared with a traditional training department. For instance, one COU, that measure its performances relying on the satisfaction of line managers, emphasize that the COU evaluation system is a tool to increase the awareness of the importance of training across the entire organization. Another $\mathrm{COU}$ is in charge for developing and integrating evaluation systems to be applied to the entire parent company. In another case the goal of the evaluation system is to assess the needs of the internal customer in order to continuously innovate 
the training activities of the COU and increase their quality. Overall, it seems, on the one hand, that the COUs acknowledge the critical nexus between evaluation system, performance indicators and potential effects on efficiency, but, on the other hand, that their wider scope and range of external actors do not allow them to stick to a unique model. Thus, the COUs try to strengthen this link through original paths that need to involve external actors and develop new indicators in order to tailor an appropriate evaluation system. This evidence raises the need to give a further look across the COUs with regard to their mission and relationship with external stakeholders.

\subsection{Objectives and relationship with external stakeholders}

Table 6 shows our findings on COU's objectives and drivers as derived from the reasons-motives underlying the establishment of the $\mathrm{COU}_{2}$ and the mission of the $\mathrm{COU}$, if declared. By analysing the content of the unstructured answers on the rationale of the COU's establishment we have drawn a set of eight categories of drivers of the COU. On the other hand, by looking at the mission statement of the COU, if existing, we identify three tyope of objectives pursued by the COUs. Basing on these criteria, the need for integration of employees and dissemination of corporate culture emerges as the primary factor driving the establishment of the COUs $(70 \%)$. This demand comes in particular from firms undertaking mergers and acquisitions, from multinational companies, and from firms ensuring high behavioural standards to their customers. In some case this motivation is associated with the objective of disseminating knowledge throughout the organization (30\%). For about half of the respondents the COU is driven by the presidium of core competences (50\%) and the development of managerial skills $(60 \%)$. Other reasons are less frequent: systematic interaction with external stakeholders (25\%), recruitment and integration of talents $(20 \%)$, creation of new knowledge (20\%), cost savings (10\%). Consistently with these answers, the vast majority of the COUs $(90 \%)$ plays a role in spreading the corporate culture throughout the firm and in integrating talents in the organization. Similarly, $80 \%$ of COUs underline their role in preserving and disseminating knowledge. Conversely, the role of the COU in addressing change and fostering innovation seem to emerge only in an ex-post perspective. Despite the limited number of COUs that designate the relationship between innovation and training as a driver of the establishment of the $\mathrm{COU}, 85 \%$ of the sample acknowledged that the COU gives a contribute in fostering creativeness, innovation and change. Less common, but still significant, is the role of the COU in supporting Corporate Social Responsibility (CSR) practices, reported by $55 \%$ of the sample. 
$<$ Table 6>

Concerning external relationships, the whole sample keeps stable relationships with traditional universities, thus confirming that their interaction grounds on cooperation rather than competition. This relationship comes from the awareness of the managers of the COUs that "light" structures are not compatible with the necessities of a proper training agency in charge for the entire learning process. Moreover, COUs are aware that firms' competitiveness often grounds on knowledge coming from traditional universities and research centres. There are many ways, however, in which such cooperation takes place (Table 7). A partnership with traditional universities, defined by means of special agreements, is in place in $80 \%$ of interviewed COUs, while common lectures, which assume a more active role of the $\mathrm{COU}$, are activated by $60 \%$ of them. Agreements for hiring young graduates and organizing recruitment events in collaboration with traditional universities are signed by $70 \%$ of the COUs. This result is in line with the frequent attribution of selection and recruitment activities to the COUs. The only kind of interaction that is not widespread $(10 \%)$ is the provision of joint courses or the delivery of common master's degrees.

$<$ Table 7>

Other stakeholders involved in COU activities (Table 8) are represented by educational agencies and consulting services, which are usually related to the $\mathrm{COU}$ for the need for external lecturers expressed (50\%). Trade associations interact with $50 \%$ of the COUs for defining activities and joint programs within the industry, while research centres are involved by $30 \%$ of the COUs for carrying out specific research or joining R\&D functions. Only $25 \%$ of the COUs sign agreements with schools and organize training courses with the primary objective of hiring former students. In one case public government asks the COU for providing training activities to high-school students. Finally, while most of the COUs have built a network of relationships with traditional universities, business schools, training centres, consultants, industry experts, only some of them have established stable partnership targeted to the promotion of innovation and change in the sponsoring firm.

$<$ Table $8>$ 
Once interacted the results on objectives and relationship with external stakeholders, we use our taxonomy to divide the COUs according to their role in knowledge production/exchange. In this respect, our work confirms the existence of different types of COUs: most of them can be considered as either leaders (65\%) or gatekeepers $(25 \%)$ while only $10 \%$ falls in the "R\&D engine" category. This means that COUs evaluation needs are highly complex and partly differentiated. The need to provide useful indicators to the wide number of involved stakeholders, which is typical of the "gatekeepers", should be associated with the importance to include indicators that measure the COUS' capability to contribute to innovation and change in the case of "leaders". However, as previously reported, Italian COUs and their parent companies have not developed such tailored indicators or, at least they have not included them in their evaluation system yet.

\section{Conclusions}

Many companies around the world are investing directly in higher education units, like corporate universities._There are two circumstances that may have favored the rise of these units: companies need to manage the acquisition and retention of new knowledge in order to increase their competitive advantage while universities are engaged in imagining how to accomplish the task of so-called third mission that has been entrusted. The COUs may represent a sort of neutral ground, a field between two now rather distant systems.

This paper discusses the evaluation of COU performance by using the results of an original survey delivered to the Italian COUs. By addressing the issue of the evaluation of their performance, this paper confirms that COUs are complex entities which encompass wider scopes and objectives, and a larger number of external stakeholder than traditional training departments.

Given that more than one theory could provide a suitable framework for analysing the evaluation of COU training initiatives, the stakeholder-based approach is the one that enables all the multiple categories of actors that are interested in the COU's performance to be involved in the evaluation process. However, we argue that, although Kirkpatrick's hierarchical model still partially fits with the evaluation of COUs activities, to the extent to which training is deemed as the core activity of these entity, a comprehensive assessment of their outcome should go beyond this model.

In particular, the different nature of the COUs in terms of audience, external stakeholders, motivations and objectives implies the differentiation of the performance aspects to be evaluated in order to take into account the actual role of the COUs with respect to the production and exchange of knowledge between the sponsoring firm and the external system, typically represented by 
traditional universities and other research centers. In line with this reasoning, we propose as a criterion for evaluating the activities of the COU management mode of knowledge and particularly the ability to produce new knowledge and readiness to interact with external parties to exchange it. According to this method, the leading companies are those that generate new knowledge and share it with others. In this way, companies will qualify as "public" actors or entities that contribute to community development by providing development and innovation. Insofar as they are more similar to internal units focused on training a hierarchical-based evaluation system integrated with indicators that take into can be applied. On the other hand, if the COU acts as a knowledge "gatekeeper" stakeholder-based approach is more consistent with the peculiar nature of these entities when dealing with knowledge. Thus, together with the adoption of a stakeholder-based approach, as suggested by Guerci et al. (2001), the aspects of innovation and strategic orientation can be addressed by an appropriate taxonomy based on the combination between COUs' scope, mission, and external stakeholders.

Finally, the main limitation of this study is the limited scope of the survey which is limited to Italy. Moreover, the findings reflect the state of the art at the time of the study; without tracing the intertemporal evolution of the COU evaluation systems. Future research on this topic could address these issues by looking at a sample of European COUs while considering external demographic and environmental that may influence the overall characteristics of the performance evaluation of the COUs.

\section{References}

Abel A.L., Li J. (2012), Exploring the Corporate University Phenomenon: Development and Implementation of a Comprehensive Survey, Human Resource Development Quarterly, 23, 1, pp. 103-124.

Allen M. (2002). Introduction. What is a corporate university and why should an organization have one? In M. Allen (Ed.), The Corporate University Handbook. Designing, Managing and Growing a Successful Program (pp. 1-14). New York: AMACOM.

Allen, M. (2007). What is a Next-generation Corporate University? In M. Allen (Ed.), The Next Generation of Corporate Universities (pp. 3-16). San Francisco: John Wiley and Sons.

Allen, M. (2009). Expanding the Value of Corporate Universities: The Stakeholder Approach. In A. Romano \& G. Secundo (Eds.), Dynamic Learning Networks. Models and Cases in Action (pp.121136), New York: Springer. 
Allen, M. (2010). Corporate universities 2010: globalization and greater sophistication. The Journal of International Management Studies, 5, 48-53.

Antonelli, G., Cappiello, G. \& Pedrini G. (2013). The Corporate university in the European utility industries. Utilities Policy, 25, 33-41.

Blass, E. (2005). The Rise and The Rise of Corporate University. Journal of European industrial training, 29, 58-74.

Bober, C. \& Bartlett, K. (2004). The utilization of training program evaluation in corporate universities. Human Resource Development Quarterly, 15, 363-388.

Cappiello, G., \& Pedrini, G. (2013). Le corporate university italiane, L'Industria, 2/2013, 295-328.

El-Tannir, A. (2002). The corporate university model for continuous learning, training and development. Education \& Training, 44 (2), 76-81.

Eurich, N.P. (1985). Corporate Classroom: the Learning Business. Princeton: Carnegie Foundation.

Grant, R.M. (1996). Prospering in dynamically-competitive environments: organizational capability as knowledge integration. Organization Science, 7, 375-387.

Guerci, M., Bartezzaghi, E. \& Solari L. (2011). Training evaluation in Italian corporate universities: a stakeholder-based analysis. International Journal of Training and Development, 14, 291-308.

Henley Management College (2005). What are...corporate universities?. The Times, $13^{\text {th }}$ January, Career, p. 8.

Jarvis, P. (2001). Universities and Corporate Universities. London: Kogan Page.

Kauppila, O., Mursula, A., Harkonen, J. \& Kujala, J. (2015). Evaluating university-industry collaboration: the European Foundation of Quality Management excellence model-based evaluation of university-industry collaboration. Tertiary Education and Management, 21, 229-244.

Kiely, L. (2002), Measurement in corporate university learning environments: Is it gonna show? Do we wanna know? In Allen M. (Ed.), The Corporate University Handbook. Designing, Managing and Growing a Successful Program. New York: Amacom.

Kirkpatrick, D. L. (1994). Evaluating Training Programs: The Four Levels. San Francisco: BerrettKoehler.

Maglione, R. \& Passiante, G. (2009). The stakeholder university as dynamic learning network: The Finmeccanica case. In A. Romano \& G. Secundo (Eds.), Dynamic Learning Networks: Model and Cases in Action (pp.95-120), New York, Springer.

Margherita, A., \& Secundo, G. (2009). The Emergence of the Stakeholder University. In A. Romano (Ed.), Open Business Innovation Leadership. The emergence of the Stakeholder University (pp. 170-207), London: Palgrave MacMillan. 
Mc Ateer, P., \& Pino, M. (2011). The business case for creating a corporate university. New York: Corporate University Xchange.

Meister, J.C. (1998). Corporate Universities. Lessons in Building a World-class Workforce, New York, McGraw-Hill.

Moore, J.D. (2002). Running a Corporate University Like a Business: a Financial Model. In M. Allen (Ed.), The Corporate University Handbook. Designing, Managing and Growing a Successful Program (pp. 33-42). New York: Amacom.

Morin, L. \& Renaud, S. (2004). Participation in corporate university training: its effect on individual job performance. Canadian Journal of Administrative Science, 21, 295-306.

Paton, R. (2005). Reviewing and Reporting Results. In R. Paton, G. Peters, J. Storey \& S. Taylor (Eds), Handbook of Corporate University Development (pp. 123-33), Aldershot: Gower,.

Patton, M. Q. (1997). Utilization-Focused Evaluation: The New Century Text. Thousand Oaks: Sage.

Philips, J. (1997). Handbook of Training Evaluation and Measurement Methods. Houston: Gulf.

Rademakers, M. (2005). Corporate Universities: Driving Force of Knowledge Innovation. Journal of Workplace Learning, 17, pp. 130-136.

Renaud-Coulon A. (2008). Corporate Universities: a Lever of Corporate Responsibility. Paris: Global CCU Publishing.

Rheaume, L., \& Gardoni, M. (2015). The challenge facing corporate universities in dealing with open innovation. Journal of Workplace Learning, 27, 315-328.

Wang, G., Li, J., Qiao, X. \& Sun, J. (2010). Understanding the corporate university phenomenon: a human capital theory perspective. International Journal of Human Resource Development and Management, 10, 182-204.

Walton, J. (2005). Would the Real Corporate University Please Stand Up? Journal of European Industrial Training, 29, pp. 7-20. 
Table 1-The COU as a knowledge-based entity

\begin{tabular}{c|c|c|c|} 
& \multicolumn{3}{|c|}{ Knowledge exchange } \\
\hline \multirow{3}{*}{ Knowledge production } & & - & + \\
\cline { 2 - 4 } & + & R\&D Engine & Innovation leader \\
\cline { 2 - 4 } & - & Follower & Gatekeeper \\
\cline { 2 - 4 } & & & \\
\hline
\end{tabular}

1

2

3

4

5

6

10

11

12

13

14

15

16

17

18

19

20

21

22

23

24

25

26

27

28

29

30

31

32

33

34

35

36

37

38

39

40

41

42

43

44

45

46

47

48

49

50

51

52

53

54

55

56

57

58

59

60 
1

2

Table 2-Financial sources of the COU

\begin{tabular}{lc}
\hline Financial sources of the COU & Percentage \\
\hline Autonomous budget allocated by the top management & $55 \%$ \\
Training budget & $60 \%$ \\
External funds (public subsidies, etc.) & $60 \%$ \\
Students' contributions & $20 \%$ \\
\hline
\end{tabular}


Table 3 - Students

\begin{tabular}{lc}
\hline COU students & Percentage \\
\hline Top Management & $90 \%$ \\
Middle Management & $95 \%$ \\
Operating staff & $75 \%$ \\
Customers & $30 \%$ \\
Agents, Consultants & $30 \%$ \\
Young graduates & $25 \%$ \\
Suppliers & $10 \%$ \\
\hline
\end{tabular}

URL: http:/mc.manuscriptcentral.com/rtem 
2

8

9

Table 4- Training subjects

\begin{tabular}{lc}
\hline Contents & Percentage \\
\hline General management & $80 \%$ \\
Corporate culture and business mission & $85 \%$ \\
Informational system & $45 \%$ \\
Organizational change & $70 \%$ \\
Leadership and communication & $90 \%$ \\
Problem solving & $70 \%$ \\
Team building & $75 \%$ \\
Time management and stress management & $60 \%$ \\
Specific competences related to firm's business & $90 \%$ \\
Specific competences related to the relevant industry & $65 \%$ \\
Administration (accounting, payrolls, etc.) & $55 \%$ \\
Marketing and sales & $70 \%$ \\
Foreign languages & $70 \%$ \\
Safety and environmental sustainability & $50 \%$ \\
\hline
\end{tabular}


Table 5 - Performance criteria and hierarchical levels

\begin{tabular}{lc}
\hline Effectiveness indicators & Percentage \\
\hline Learning & $75 \%$ \\
Employees' approval and climate surveys & $65 \%$ \\
Internal customer satisfaction & $35 \%$ \\
Training output (quantitative indicators) & $25 \%$ \\
Workers' productivity & $25 \%$ \\
Acquired competences & $15 \%$ \\
Lecturers & $10 \%$ \\
Skills matching & $5 \%$ \\
Career paths & $5 \%$ \\
\hline Hierarchical model: levels & Percentage \\
\hline Level 1 & $65 \%$ \\
Level 2 & $75 \%$ \\
Level 3 & $25 \%$ \\
Level 4 & $40 \%$ \\
Level 5 & $0 \%$ \\
\hline
\end{tabular}


2

Table 6-Mission and drivers of the COUs

\begin{tabular}{|c|c|c|c|c|c|}
\hline $\begin{array}{ll}\text { Drivers* } & \text { Mission } \\
\end{array}$ & $\begin{array}{c}\text { Human capital } \\
\text { development }\end{array}$ & $\begin{array}{c}\text { Support of } \\
\text { business strategies }\end{array}$ & $\begin{array}{c}\text { Response to } \\
\text { change }\end{array}$ & No mission & Total \\
\hline $\begin{array}{l}\text { Employees integration } \\
\text { and knowledge sharing }\end{array}$ & $25 \%$ & $15 \%$ & $15 \%$ & $15 \%$ & $70 \%$ \\
\hline $\begin{array}{l}\text { Development of } \\
\text { managerial competences }\end{array}$ & $25 \%$ & $10 \%$ & $15 \%$ & $10 \%$ & $60 \%$ \\
\hline $\begin{array}{l}\text { "Core competences" } \\
\text { strengthening }\end{array}$ & $25 \%$ & $15 \%$ & $5 \%$ & $5 \%$ & $50 \%$ \\
\hline $\begin{array}{l}\text { Systematization of the } \\
\text { relationships with } \\
\text { external stakeholders. }\end{array}$ & $10 \%$ & $5 \%$ & $5 \%$ & $5 \%$ & $30 \%$ \\
\hline $\begin{array}{l}\text { Knowledge diffusion } \\
\text { within the firm }\end{array}$ & $10 \%$ & $5 \%$ & $10 \%$ & $5 \%$ & $30 \%$ \\
\hline Talent recruitment & $10 \%$ & $5 \%$ & $0 \%$ & $5 \%$ & $20 \%$ \\
\hline Knowledge creation & $15 \%$ & $0 \%$ & $0 \%$ & $5 \%$ & $20 \%$ \\
\hline Costs savings & $5 \%$ & $0 \%$ & $0 \%$ & $5 \%$ & $10 \%$ \\
\hline
\end{tabular}

*Each corporate university may be associated with more than one driver 
Table 7 - Relationship with traditional universities

\begin{tabular}{lc}
\hline Subject of the relationships with traditional universities & Percentage \\
\hline Common lectures & $60 \%$ \\
Partnership & $80 \%$ \\
Stage agreements & $70 \%$ \\
Participation to students' and graduates' events (e.g. Career Day) & $70 \%$ \\
Mutual degree programs & $10 \%$ \\
\hline
\end{tabular}

13

14

15

16

17

18

19

20

21

22

23

24

25

26

27

28

29

30

31

32

33

34

35

36

37

38

39

40

41

42

43

44

45

46

47

48

49

50

51

52

53

54

55

56

57

58

59

60

URL: http:/mc.manuscriptcentral.com/rtem 
1

2

Table 8-Other external stakeholders

\begin{tabular}{lc}
\hline External stakeholders & Percentage \\
\hline Training companies and consultants & $50 \%$ \\
Industrial associations & $50 \%$ \\
External experts & $30 \%$ \\
Research centres & $30 \%$ \\
Schools & $25 \%$ \\
Government agencies & $5 \%$ \\
\hline
\end{tabular}


"The performance evaluation of corporate universities"

\begin{tabular}{|l|}
\hline Reviewers' comments \\
\hline Reviewer 1 \\
\hline $\begin{array}{l}\text { Your title is misleading in two different ways. } \\
\text { First, the article is not just about 'performance } \\
\text { evaluation', but provides a more rounded account } \\
\text { of the work of corporate universities }\end{array}$ \\
\hline
\end{tabular}
Author's response

Section 2 has been shortened and the article has been more centred on performance evaluation

I think at some point you need to critique the notion of 'corporate universities' rather more than you do. Clearly, for one thing, most hardly merit the title 'university' in terms of their scale.

At the beginning of Section 2 the following sentence has been added:

"In the literature, a widely accepted definition of COU is still missing and even the same term "corporate university" is in some way problematic. The main difficulty with accurately defining it rests on the diverse range of projects that are labelled with this term and on the relationship between COUs and traditional universities. In most of the cases the term "university" is used more "as a metaphor for outlining the importance of its learning initiatives and for branding the organizations' educational programs" (Maglione and Passiante, 2009, 104) than for an actual attempt to transplant the model of a traditional university into a company. Walton $(2005$, p. 8$)$ even argues that "virtually no COU would meet the requirements set out in dictionary definitions of the word "university", nor would they wish to". Still now, despite the further and diffusion and development of the phenomenon, there is little evidence of convergence between entities coming from different roots and traditions. Nor the COUs do have a formal legal status or a common worldwide standard if analysed as a standalone model."

It's curious that, though you say the survey was primarily qualitative, the results you present are essentially quantitative. Perhaps you could use some of the qualitative material to exemplify and liven up your reportage of the findings?
Non-structured answers have been used to enrich Section 5.2. Notably the following sentence has been added

This insight is partially supported by non-structured answers that exemplify the need to take into account the broader scope of the COU compared with a traditional training department. For instance, one COU, that measure its performances relying on the satisfaction of line managers, emphasize that the COU evaluation system is a tool to increase the awareness of the importance of training across the entire organization. Another $\mathrm{COU}$ is in charge for developing and integrating evaluation systems to be applied to the entire parent company. In another case the goal of the evaluation system is to assess the needs of the internal customer in order to 

'activity'?

4, 44 - I'm not sure that 'notorious' is the right word; perhaps 'popular'?

5, 11 - 'we can identify three different types' But you only identify two.

$5,23-\mathrm{Ah}$, I see your bullet points have gone wrong.

9, 20 - How did you identify the corporate universities? Did those you contacted include all there were in Italy? Can you say anything about the representativeness of the sample that responded?

$10,6-\mathrm{HRD} ?$

$13,16-\mathrm{CSR}$ ?

\section{Reviewer 2}

The term "corporate university" is problematic. In many countries it is illegal that corporations establish their own universities. Why not to call COUs human resources, training or knowledge management units. The paper does not have any discussion about the legal status of corporate universities or the tension between COUs and traditional universities.

What is the quality control of real universities in the collaboration with COUs? What is the value added of COUs compared with traditional universities?

In Section 2 the following sentence has been added "Nor the COUs do have a formal legal status or a common worldwide standard if analysed as a standalone model."

The following sentence has been added to the end of Section 3

"In such a scheme educational agencies, such as "real" universities, would be supported by "Innovators" in transferring research outcomes from university to the firms while "gatekeepers" could activating spatially idiosyncratic development processes based on tacit knowledge and proximity. In both perspectives, the COU is an autonomous unit oriented to get value from the interactions with external agencies, and from the diffusion of knowledge outside the parent company. In both cases the potential added value of the COU needs appropriate measures that go beyond the traditional indicators while traditional universities, as keyexternal stakeholders, can be entitled to exert a quality control on the COUs with which they 
cooperate."

The writing in the paper is generally good, but the writing in the paper needs some work as there We improved the quality of the writing. If accepted we are available for further proofreading.

Introduction: Add recent references, especially in Done

Para 3.

Pages 3-4, Para 3 is too long.

Page 4, line 31: Clarify and/or correct "his".

Page 5: Clarify / add "technical" in the bullet list.

Sometimes the bullet lists are as follows: 1., 2., 3 ... and in other cases a), b), c)... It is a little bit disturbing that there are so many bullet list as in the lectures. The story can be clarified.

The organization of your paper needs some work. The fourth section is rather short.

"Figure 1" seems to be a Table. It is problematic. Please clarify the Table. What are the "followers" and "gatekeepers"?

Page 8: COUs are specific units, not organizations.

Figures and Tables should be labelled clearly so that they are as much as possible understandable without the text. Clarify especially Table 4.

Page 15: too long paragraph.

You should do some work on your conclusions section. It should do the following things: 1 . Reiterate the goal of the paper, 2. Briefly discuss the data and methodology that you used to test your propositions, 3 . Summarize the primary findings in your paper, 4 . Discuss any limitations of your paper, 5. comment on directions for future research.

Double check your references to insure that everything you cite in the paper is included in the references section. Also check to make sure that everything that you are including in the reference section is cited in the paper.

Please follow the author guidelines of the journal.

\section{Reviewer 3}


Please provide some general information about how big is the COU sector in Italy and Europe, in other words about clarifying how the analysis of the sector is relevant for the interests of scholars in Higher Education
Section 2 has been shortened. Section 3 has been widened

In general, I would suggest to have less description of what Corporate Universities (COUs) are, and more focus on the topic of performance measurement and performance evaluation.

Of course, the initial part should be reinforced to make stronger and stronger arguments about the fact that COUs are part of a broadly defined $\mathrm{HE}$ sector.

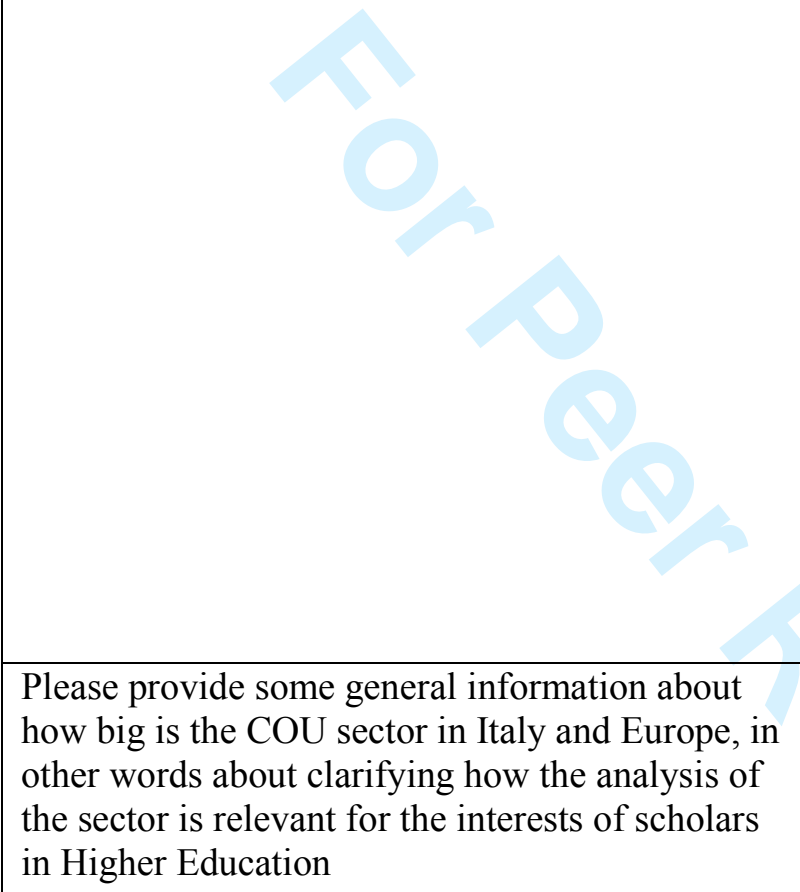

that an interesting justification at the beginning of the paper should be that analyzing performance evaluation is critical for COUs to improve their efficiency and effectiveness in pursuing and reaching their objectives - which, of course, are different than those of traditional universities
In the introduction the following sentence in Section 2 has been added:

"As such, although COUs and traditional universities have different aims, scopes and values, the COU can be considered as part of a broadly defined HE sector. Indeed, the COU substantially differs from the traditional "training and development" departments because they go beyond the provision of technical idiosyncratic skills and organizational culture by providing courses that are typical of post-school education (El-Tannir, 2005). In particular, the COU is a mean for acknowledging the central role of certain competences in sustaining the long-term growth of the firm and can be seen as a potential catalyst of knowledge able to pursuit a sustainable competitive advantage through its two cornerstone: the strategic role and the capability to integrate knowledge in order to address innovation and change (Rheaume and Gardoni, 2015).

In the Introduction the following sentence has been added.

"Historically, the COUs born in the United States where the phenomenon has been experiencing a systematic development to reach the current diffusion, approximately quantified in 4000 units (Global CCU, 2010). In parallel, a worldwide spread of COUs occurred, in particular in Western Europe, where active COUs are estimated to exceed 200 almost doubling in the last decade if compared with the number reported in the early 2000 s at least 30 of which are established in Italy (Cappiello and Pedrini, 2013)."

In the Introduction the following sentence has been added

"COUs, like other institutions, have a strong need of conducting appropriate evaluation in order to improve their efficiency and effectiveness in pursuing and reaching their objectives, which, however, are different than those of traditional universities, on the one hand, and of standard training departments, on the other hand. Not surprisingly, despite the relevance of performance evaluation for the COU and the call for a balanced approach "mixing both quantitative and qualitative criteria" (Morin and Renaud, 2004, p. 305) the 
Following some of my previous comments, I would strongly reduce the section 2 , and I would Focus it on those factors that are important for the reader to understand how you are answering the research question.

measurement of the overall effect of COU activities has been proven to be a difficult task (Bober and Barlett, 2004).

In the introduction the following sentence has been added

"Once acknowledged the heterogeneity of the COU formats both in theory and practice, the issue to be addressed is what kind of performance evaluation system is more able to improve COUs' efficiency and effectiveness with respect to the institutional objectives underlying each variety of COU. In order to address this research question, we use data of a survey on Italian COUs by looking at the organizational members that evaluates the $\mathrm{COU}$, the external stakeholders involved in COUs' activities, and the criteria used for the evaluation assessment. This paper thus contributes to the existing literature by establishing a relationship between COU evaluation systems and the different categories of COUs."

At the end of Section 2 the following sentence has been added:

"Overall, the distinctive traits of the COU, which make it more complex than a traditional training department, and the variety of the COU formats that can be actually implemented, are the distinguishing factors that help us to focus our research question. On the one hand, they emphasize the importance of the evaluation system for these entities in order to objectively demonstrate the achieved results. On the other hand, they raise the need to apply different models according to their specific scope and objectives."

In the section 3, please stress the role that indicators have in assessing the performance of COUs (and their link with efficiency), and provide more precise suggestions about how your research (I.e. Your survey) is improving the understanding of it
At the end of Section 3 the following Sentence has been added

". In such a scheme educational agencies, such as "real" universities, would be supported by "Innovators" in transferring research outcomes from university to the firms while "gatekeepers" could activating spatially idiosyncratic development processes based on tacit knowledge and proximity. In both perspectives, the COU is an autonomous unit oriented to get value from the interactions with external agencies, and from the diffusion of knowledge outside the parent company. In both cases the potential added value of the COU needs appropriate measures that go beyond the traditional indicators while traditional universities, as keyexternal stakeholders, can be entitled to exert a quality control on the COUs with which they 
The section about Results seems a bit too much descriptive. For instance, point 5.1 can be drastically reduced and I would give more space to section 5.2 - also, stressing the link between evaluation system, performance indicators and potential effects on efficiency. cooperate."

Section 5.1 has been shortened.

In Section 5.2 the following sentence has been added

"This insight is partially supported by unstructured answers that exemplify the need to take into account the broader scope of the COU compared with a traditional training department. For instance, one $\mathrm{COU}$, that measure its performances relying on the satisfaction of line managers, emphasize that the COU evaluation system is a tool to increase the awareness of the importance of training across the entire organization. Another $\mathrm{COU}$ is in charge for developing and integrating evaluation systems to be applied to the entire parent company. In another case the goal of the evaluation system is to assess the needs of the internal customer in order to continuously innovate the training activities of the COU and increase their quality. Overall, it seems, on the one hand, that the COUs acknowledge the critical nexus between evaluation system, performance indicators and potential effects on efficiency, but, on the other hand, that their wider scope and range of external actors do not allow them to stick to a unique model. Thus, the COUs try to strengthen this link through original paths that need to involve external actors and develop new indicators in order to tailor an appropriate evaluation system." 